\title{
PENGARUH TINGKAT NAUNGAN DAN CEKAMAN AIR TERHADAP PERTUMBUHAN DAN HASIL TEMULAWAK (CURCUMA XANTHORRHIZA)
}

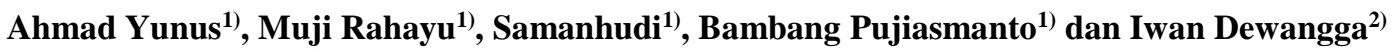 \\ ${ }^{1)}$ Program Studi Agroteknologi Fakultas Pertanian UNS \\ ${ }^{2)}$ Mahasiswa Program Studi Agroteknologi Fakultas Pertanian UNS \\ Email: yunus@staff.uns.ac.id
}

\begin{abstract}
Temulawak (Curcuma xanthorrhiza) is one of superior kind of plant which has many benefits as medicinal plants. Cultivation of temulawak not yet intensively and grown on the land under the trees. Therefore, this research was important to get shade and water stress levels appropriate for cultivation of temulawak and higher producing secondary metabolities. This research used a nested design with two treatment, that is shade (without shade, 25\%, 50\%, 75\%) and water stress (without water stress, $75 \%, 50 \%, 25 \%$ field capacity) with five replicants. Result were analyzed using analysis of variance and if there significant diference followed by DMRT 5\% level. The result showed without shade treatment increase growth of temulawak include number of leaves, fresh weight of plant and dry weight of plants, and shade 50\% increase plants height. The treatment of without water stress increase growth and yield of temulawak include number of tillers, number of leaves, fresh weight and dry weight of plants, fresh weight and dry weight of rhizomes. The levels of curcumin increase on shade $25 \%$ and water stress $25 \%$.
\end{abstract}

Keywords : shade, secondary metabolities, temulawak, water stress

\section{PENDAHULUAN}

Temulawak merupakan salah satu jenis tumbuhan dari keluarga Zingiberaceae yang banyak digunakan sebagai obat, baik dalam bentuk tunggal maupun campuran untuk meningkatkan sistem imunitas tubuh. Khasiat lain temulawak adalah anti bakteri, anti diabetik, anti hepatotoksik, anti inflamasi, anti oksidan, anti tumor, diuretika, dan hipolipodemik (Akram et al. 2010).

Pada tahun 2012 produktivitas temulawak di Indonesia sebesar 23,6 ton/ha. Tanaman ini mengalami peningkatan produksi sebesar $84,02 \%$, peningkatan luas panen sebesar $39,93 \%$ dan peningkatan produktivitas sebesar $33,33 \%$ dari tahun 2011 (BPS 2013). Kabupaten Karanganyar merupakan daerah dengan sentra produksi biofarmaka terbesar di Jawa Tengah dan telah terbentuk Klaster Biofarmaka dengan anggota 10 kelompok tani dengan luas lahan kurang lebih 270 ha.

Budidaya temulawak sebagian besar belum dilakukan secara intensif. Tanaman ini banyak ditanam di lahan di bawah tegakan dan di pekarangan yang terdapat tanaman kayu yang akan menaungi tanaman-tanaman dibawahnya. Pada budidaya temulawak ketersediaan air sangat bergantung pada intensitas curah hujan karena sebagian besar lahan di Karanganyar adalah lahan kering dan petani jarang melakukan penyiraman. Oleh karena itu, penelitian tentang faktor cekaman air dan intensitas naungan penting untuk dilakukan untuk memperoleh kondisi lingkungan tumbuh yang sesuai untuk budidaya temulawak dan meningkatkan kandungan metabolit sekundernya.

\section{METODE PENELITIAN}

Penelitian dilaksanakan mulai Juni 2013 sampai Juni 2014 di Desa Pendem, Kecamatan Mojogedang, Kabupaten Karanganyar dengan letak geografis $07^{\circ} 33^{\prime} 31,1^{\prime}$ ' LS dan $111^{\circ} 01^{\prime}$ 48,4" BT dan ketinggian 365 meter diatas permukaan laut (mdpl), Laboratorium Kimia dan Kesuburan Tanah, dan Laboratorium Pangan dan Gizi Fakultas Pertanian Universitas Sebelas Maret (UNS) Surakarta.

Bahan yang digunakan dalam penelitian adalah bibit/rimpang temulawak, pupuk kandang sapi, tanah, pupuk urea, pupuk $\mathrm{KCl}$, pupuk SP36, etanol, dan larutan standar baku kurkumin. Alat yang digunakan adalah bambu, plastik, polibag, cangkul, cetok, gelas ukur 1 liter, timbangan digital, penggaris, naungan/paranet $25 \%, 50 \%$, dan $75 \%$, soil moisture tester, Spektrofotometer, dan tabung reaksi.

Penelitian ini menggunakan rancangan tersarang (Nested) terdiri dari dua faktor 
perlakuan dengan lima kali ulangan sehingga diperoleh 80 sampel tanaman. Faktor pertama yaitu naungan $(\mathrm{N})$, meliputi tanpa naungan (N1), naungan $25 \%(\mathrm{~N} 2)$, naungan $50 \%(\mathrm{~N} 3)$, dan naungan $75 \%$ (N4). Faktor kedua adalah cekaman air (C), meliputi tanpa cekaman air (C0), cekaman air 25\% KL (kapasitas lapang) (C1), cekaman air 50\% KL (C2), dan cekaman air $75 \%$ KL (C3). Hasil dianalisis menggunakan analisis ragam dan apabila terdapat beda nyata dilanjutkan dengan DMRT taraf $5 \%$.

\section{HASIL DAN PEMBAHASAN}

\section{Komponen Pertumbuhan}

1. Tinggi Tanaman

Berdasarkan hasil analisis ragam, perlakuan tingkat naungan berpengaruh nyata terhadap tinggi tanaman, tetapi perlakuan cekaman air tidak berpengaruh nyata terhadap tinggi tanaman. Hasil uji lanjut pengaruh tingkat naungan terhadap tinggi tanaman temulawak disajikan dalam tabel 1 .

Tabel 1. Pengaruh tingkat naungan terhadap tinggi temulawak

\begin{tabular}{cc}
\hline Perlakuan & Tinggi $(\mathrm{cm})$ \\
\hline Tanpa naungan & $163,70 \pm 3,72 \mathrm{a}$ \\
Naungan 25\% & $180,95 \pm 1,48 \mathrm{~b}$ \\
Naungan 50\% & $196,50 \pm 3,08 \mathrm{c}$ \\
Naungan 75\% & $170,60 \pm 3,73 \mathrm{a}$ \\
\hline
\end{tabular}

Keterangan: Angka yang diikuti huruf yang sama pada satu kolom menunjukkan tidak beda nyata pada DMRT taraf 5\%.

Pada perlakuan tanpa naungan, naungan $25 \%$, dan naungan $50 \%$ tinggi tanaman meningkat yaitu $163,70 \mathrm{~cm}, 180,95$ $\mathrm{cm}$, dan 196,50 cm, kemudian menurun kembali pada naungan $75 \%$ sebesar 170,60 $\mathrm{cm}$. Hal ini sesuai dengan hasil penelitian Yusron (2009) dan Rahardjo (2010) yang menerangkan bahwa tanaman temu-temuan pada umumnya merupakan tanaman yang tahan naungan, tetapi pertumbuhan dan hasil yang maksimal diperoleh pada kisaran tingkat naungan $25 \%$ dan akan menurun jika tingkat naungan lebih dari 50\%. Tanaman akan tumbuh lebih tinggi saat ditanam di bawah naungan (Bhuiyan et al. 2012, Thohirah et al. 2010). Salisbury dan Ross (1995) menyatakan bahwa tanaman yang terkena banyak naungan akan mengalami pemanjangan sel, khususnya pada batang. Hal ini terjadi karena produksi auksin pada pucuk meningkat sehingga merangsang pemanjangan sel tanaman.

2. Jumlah Tunas

Hasil analisis ragam menunjukkan bahwa perlakuan tingkat naungan tidak berpengaruh nyata terhadap jumlah tunas, hal ini sesuai dengan penelitian Ferry et al. (2009), jumlah tunas temulawak cenderung sama saat ditanam di lahan dengan berbagai tingkat naungan. Perlakuan cekaman air berpengaruh nyata terhadap jumlah tunas. Hasil uji lanjut pengaruh cekaman air terhadap jumlah tunas disajikan pada tabel 2 .

Tabel 2. Pengaruh cekaman air terhadap jumlah tunas temulawak

\begin{tabular}{ccccc}
\hline Perlakuan & Tanpa naungan & Naungan 25\% & Naungan 50\% & Naungan 75\% \\
\hline Tanpa cekaman air & $5,6 \pm 0,24 \mathrm{~b}$ & $4,8 \pm 0,37 \mathrm{~d}$ & $5,0 \pm 0,32 \mathrm{fg}$ & $4,8 \pm 0,37 \mathrm{i}$ \\
Cekaman air 25\% KL & $4,4 \pm 0,40 \mathrm{a}$ & $4,6 \pm 0,24 \mathrm{~d}$ & $4,2 \pm 0,37 \mathrm{ef}$ & $3,6 \pm 0,60 \mathrm{~h}$ \\
Cekaman air 50\% KL & $5,8 \pm 0,49 \mathrm{~b}$ & $3,4 \pm 0,40 \mathrm{c}$ & $4,0 \pm 0,45 \mathrm{ef}$ & $3,4 \pm 0,51 \mathrm{~h}$ \\
Cekaman air 75\% KL & $4,0 \pm 0,55 \mathrm{a}$ & $2,6 \pm 0,40 \mathrm{c}$ & $3,2 \pm 0,20 \mathrm{e}$ & $3,8 \pm 0,20 \mathrm{hi}$ \\
\hline
\end{tabular}

Keterangan: Angka yang diikuti huruf yang sama pada satu kolom menunjukkan tidak beda nyata pada DMRT taraf 5\%.

Perlakuan tanpa cekaman air menunjukkan jumlah tunas paling tinggi dan cekaman air $75 \%$ KL memberikan hasil jumlah tunas yang paling rendah. Hal ini disebabkan cekaman kekeringan dapat menurunkan laju pertumbuhan tanaman pada fase vegetatif (Ai 2011). Penelitian pada tanaman jahe emprit oleh Sari et al. (2006) menunjukkan bahwa penurunan jumlah air menyebabkan penurunan aktivitas fotosintesis sehingga ketersediaan karbohidrat menurun. Karbohidrat sangat diperlukan untuk proses 
awal pembentukan jaringan seperti akar, tunas, dan daun.

3. Jumlah Daun

Berdasarkan hasil analisis ragam perlakuan tingkat naungan dan cekaman air berpengaruh nyata terhadap jumlah daun temulawak. Hasil uji lanjut pengaruh naungan dan cekaman air terhadap jumlah daun disajikan pada tabel 3.

Tabel 3. Pengaruh naungan dan cekaman air terhadap jumlah daun temulawak

\begin{tabular}{cccccc}
\multirow{2}{*}{ Perlakuan } & $\begin{array}{c}\text { Tanpa } \\
\text { cekaman air }\end{array}$ & $\begin{array}{c}\text { Cekaman } \\
25 \%\end{array}$ & $\begin{array}{c}\text { Cekaman } \\
50 \%\end{array}$ & \multirow{2}{*}{ Cekaman 75\% } & \multirow{2}{*}{ Rata-rata } \\
\cline { 1 - 5 } Tanpa naungan & $25,40 \pm 2,74 \mathrm{~b}$ & $22,60 \pm 2,24 \mathrm{~b}$ & $26,00 \pm 2,58 \mathrm{~b}$ & $16,80 \pm 1,85 \mathrm{a}$ & $22,70 \pm 1,38 \mathrm{a}$ \\
Naungan 25\% & $17,20 \pm 1,52 \mathrm{c}$ & $18,80 \pm 0,37 \mathrm{c}$ & $15,00 \pm 1,48 \mathrm{c}$ & $16,00 \pm 1,14 \mathrm{c}$ & $16,75 \pm 0,68 \mathrm{c}$ \\
Naungan 50\% & $21,00 \pm 1,30 \mathrm{~d}$ & $19,40 \pm 1,02 \mathrm{~d}$ & $18,00 \pm 1,14 \mathrm{~d}$ & $20,40 \pm 0,50 \mathrm{~d}$ & $19,70 \pm 0,54 \mathrm{~d}$ \\
Naungan 75\% & $18,80 \pm 0,86 \mathrm{e}$ & $15,60 \pm 0,24 \mathrm{e}$ & $15,20 \pm 0,37 \mathrm{e}$ & $15,20 \pm 0,86 \mathrm{e}$ & $16,20 \pm 0,46 \mathrm{e}$ \\
\hline
\end{tabular}

Keterangan: Angka yang diikuti huruf yang sama pada satu kolom menunjukkan tidak beda nyata pada DMRT taraf 5\%.

Perlakuan tanpa naungan memiliki jumlah daun paling tinggi yaitu sebesar 22,70 helai. Perlakuan tersebut berbeda nyata dengan perlakuan naungan $25 \%, 50 \%$, dan $75 \%$. Peningkatan tingkat naungan mengakibatkan penurunan jumlah daun. Intensitas cahaya yang rendah akan menurunkan fungsi stomata pada tanaman (Hossain et al. 2009). Fitter dan Hay (1992) menyatakan bahwa penurunan stomata pada daun akan memotong suplai $\mathrm{CO}_{2}$ sehingga fotosintesis terhambat dan fotosintat yang terbentuk sedikit sehingga sangat mempengaruhi pembentukan daun. Hal ini sesuai dengan penelitian beberapa jenis Curcuma, pada kondisi tanpa naungan memiliki jumlah daun yang paling banyak (Sukarjo 2004).

Berkurangnya ketersediaan air pada tanaman menyebabkan penurunan turgor sel sehingga stomata menutup (Chaum et al. 2005; Sari et al. 2006). Cekaman kekeringan dapat menurunkan jumlah daun (Bae et al. 2013), dan serapan hara akibatnya laju fotosintesis menurun sehingga produktivitas menurun (Islami dan Utomo 1995).

4. Berat Segar dan Berat Kering Tanaman

Berdasarkan hasil analisis ragam, perlakuan tingkat naungan dan cekaman air berpengaruh nyata terhadap berat segar dan berat kering tanaman (tabel 4 dan tabel 5).

Tabel 4. Pengaruh cekaman air terhadap berat segar tanaman

\begin{tabular}{cccccc}
\hline Perlakuan & $\begin{array}{c}\text { Tanpa } \\
\text { cekaman }\end{array}$ & $\begin{array}{c}\text { Cekaman air } \\
25 \% \mathrm{KL}\end{array}$ & $\begin{array}{c}\text { Cekaman air } \\
50 \% \mathrm{KL}\end{array}$ & $\begin{array}{c}\text { Cekaman air } \\
75 \% \mathrm{KL}\end{array}$ & Rata-rata \\
\hline $\begin{array}{c}\text { Tanpa } \\
\text { naungan }\end{array}$ & $447,30 \pm 23,9 \mathrm{bc}$ & $540,78 \pm 30,5 \mathrm{c}$ & $439,42 \pm 35,3 \mathrm{~b}$ & $274,60 \pm 25,8 \mathrm{a}$ & $425,525 \pm 25,75 \mathrm{c}$ \\
Naungan & $383,06 \pm 29,8 \mathrm{f}$ & $364,12 \pm 28,0$ ef & $312,26 \pm 18,3 \mathrm{de}$ & $238,32 \pm 23,3 \mathrm{~d}$ & $324,441 \pm 17,32 \mathrm{bc}$ \\
25\% & & & & & \\
Naungan & $348,76 \pm 26,3 \mathrm{~h}$ & $334,96 \pm 13,7 \mathrm{~h}$ & $207,66 \pm 17,5 \mathrm{~g}$ & $207,08 \pm 49,6 \mathrm{~g}$ & $274,615 \pm 20,78 \mathrm{ab}$ \\
$\quad 50 \%$ & & & & & \\
Naungan & $292,84 \pm 18,5 \mathrm{i}$ & $299,20 \pm 28,4 \mathrm{i}$ & $227,36 \pm 57,6 \mathrm{i}$ & $249,72 \pm 25,8 \mathrm{i}$ & $267,280 \pm 17,83 \mathrm{a}$ \\
$75 \%$ & &
\end{tabular}

Keterangan: Angka yang diikuti huruf yang sama pada satu kolom menunjukkan tidak beda nyata pada DMRT taraf 5\%. 
Tabel 5. Pengaruh cekaman air terhadap berat kering tanaman

\begin{tabular}{cccccc}
\hline \multirow{2}{*}{ Perlakuan } & $\begin{array}{c}\text { Tanpa } \\
\text { dicekam }\end{array}$ & $\begin{array}{c}\text { Cekaman air } \\
25 \% \mathrm{KL}\end{array}$ & $\begin{array}{c}\text { Cekaman air } \\
50 \% \mathrm{KL}\end{array}$ & $\begin{array}{c}\text { Cekaman air } \\
\text { T5\% KL }\end{array}$ & \multirow{2}{*}{ Rata-rata } \\
\hline Tanpa naungan & $34,57 \pm 2,19 \mathrm{c}$ & $27,60 \pm 0,91 \mathrm{~b}$ & $20,86 \pm 1,50 \mathrm{a}$ & $22,04 \pm 1,02 \mathrm{a}$ & $26,26 \pm 1,42 \mathrm{a}$ \\
Naungan 25\% & $18,29 \pm 1,29 \mathrm{de}$ & $21,56 \pm 1,04 \mathrm{ef}$ & $18,39 \pm 1,63 \mathrm{de}$ & $14,82 \pm 2,05 \mathrm{~d}$ & $18,26 \pm 0,89 \mathrm{a}$ \\
Naungan 50\% & $20,45 \pm 1,60 \mathrm{i}$ & $20,44 \pm 2,75 \mathrm{hi}$ & $18,60 \pm 2,04 \mathrm{gh}$ & $14,82 \pm 1,63 \mathrm{~g}$ & $18,58 \pm 1,08 \mathrm{a}$ \\
Naungan 75\% & $18,21 \pm 1,58 \mathrm{k}$ & $20,65 \pm 2,39 \mathrm{kl}$ & $21,42 \pm 1,721$ & $13,08 \pm 1,67 \mathrm{j}$ & $18,34 \pm 1,13 \mathrm{a}$ \\
\hline
\end{tabular}

Keterangan: Angka yang diikuti huruf yang sama pada satu kolom menunjukkan tidak beda nyata pada DMRT taraf 5\%.

Naungan $75 \%$ memberikan hasil berat segar dan berat kering paling rendah. Faktor utama yang mempengaruhi peningkatan bobot kering total hasil panen adalah radiasi matahari (Kurniawati et al. 2005). Hal ini sesuai dengan penelitian Sukarjo (2004), pada beberapa jenis Curcuma mengalami penurunan berat segar dan kering akibat penambahan tingkat naungan. Menurut Sirait (2006), naungan yang diberikan mengakibatkan menurunnya intensitas cahaya matahari yang berpengaruh pada proses-proses yang terjadi di dalam tanaman antara lain fotosintesis, respirasi, transpirasi, dan penuaan (senescence).

Cekaman air $75 \%$ memberikan hasil yang terendah karena menyebabkan jumlah air dalam tanaman berkurang sehingga stomata menutup dan mengakibatkan proses fotosintesis terhambat sehingga jumlah asimilat yang dihasilkan oleh tanaman semakin berkurang (Chaves et al. 2002). Laju fotosintesis yang lebih rendah akan menyebabkan penurunan dari hasil tanaman dan begitu juga sebaliknya (Badiane et al. 2012). Ditambahkan pula oleh Ramos et al. (2003) bahwa menurunnya bobot kering tajuk akibat cekaman air ini disebabkan karena menurunnya kemampuan tanaman dalam menyerap air dan hara di dalam tanah. Tanaman yang mengalami kekurangan air secara umum mempunyai ukuran lebih kecil dibandingkan dengan tanaman yang tumbuh normal (Kurniasari et al. 2010).

\section{Komponen Hasil}

1. Berat Segar dan Berat Kering Rimpang Temulawak

Berdasarkan hasil analisis ragam, perlakuan naungan tidak berpengaruh nyata terhadap berat segar dan berat kering rimpang temulawak. Hasil uji lanjut pengaruh tingkat cekaman air terhadap berat segar dan berat kering rimpang temulawak disajikan pada tabel 6 dan tabel 7 .

Tabel 6. Pengaruh cekaman air terhadap berat segar rimpang temulawak

\begin{tabular}{ccccc}
\hline Perlakuan & Tanpa naungan & Naungan 25\% & Naungan 50\% & Naungan 75\% \\
\hline Tanpa dicekam & $770,602 \pm 55,6 \mathrm{c}$ & $743,516 \pm 42,3 \mathrm{f}$ & $537,022 \pm 76,8 \mathrm{i}$ & $484,634 \pm 40,91$ \\
Cekaman air 25\% KL & $506,704 \pm 66,7 \mathrm{bc}$ & $401,964 \pm 52,6 \mathrm{e}$ & $340,61 \pm 52,6 \mathrm{gh}$ & $313,344 \pm 19,2 \mathrm{kl}$ \\
Cekaman air 50\% KL & $448,724 \pm 23,6 \mathrm{~b}$ & $338,890 \pm 18,21 \mathrm{e}$ & $293,840 \pm 31,1 \mathrm{~g}$ & $187,338 \pm 9,6 \mathrm{j}$ \\
Cekaman air 75\% KL & $207,154 \pm 39,1 \mathrm{a}$ & $216,398 \pm 15,07 \mathrm{~d}$ & $257,440 \pm 20,3 \mathrm{~g}$ & $204,348 \pm 26,3 \mathrm{jk}$ \\
\hline
\end{tabular}

Keterangan: Angka yang diikuti huruf yang sama pada satu kolom menunjukkan tidak beda nyata pada DMRT taraf 5\%.

Tabel 7. Pengaruh cekaman air terhadap berat simplisia temulawak

\begin{tabular}{ccccc}
\hline Perlakuan & Tanpa naungan & Naungan 25\% & Naungan 50\% & Naungan 75\% \\
\hline Tanpa dicekam & $82,60 \pm 5,05 \mathrm{c}$ & $73,26 \pm 9,58 \mathrm{f}$ & $75,00 \pm 8,80 \mathrm{i}$ & $73,04 \pm 5,84 \mathrm{l}$ \\
Cekaman air 25\% KL & $73,00 \pm 4,73 \mathrm{ab}$ & $60,34 \pm 9,58 \mathrm{ef}$ & $60,12 \pm 5,80 \mathrm{hi}$ & $56,66 \pm 5,20 \mathrm{kl}$ \\
Cekaman air 50\% KL & $73,28 \pm 4,53 \mathrm{bc}$ & $59,96 \pm 3,94 \mathrm{de}$ & $48,26 \pm 3,82 \mathrm{gh}$ & $51,28 \pm 5,13 \mathrm{jk}$ \\
Cekaman air 75\% KL & $55,40 \pm 11,26 \mathrm{a}$ & $42,44 \pm 5,67 \mathrm{~d}$ & $44,82 \pm 6,89 \mathrm{~g}$ & $34,98 \pm 3,75 \mathrm{j}$ \\
\hline
\end{tabular}

Keterangan: Angka yang diikuti huruf yang sama pada satu kolom menunjukkan tidak beda nyata pada DMRT taraf $5 \%$. 
Cekaman air 75\% menunjukkan hasil berat segar dan berat kering rimpang yang rendah. Pada saat kekurangan air, sebagian stomata daun menutup sehingga terjadi hambatan masuknya $\mathrm{CO}_{2}$ dan menurunkan aktivitas fotosintesis (Kurniasari et al. 2010). Laju fotosintesis yang lebih rendah akan menyebabkan penurunan dari hasil tanaman dan begitu juga sebaliknya (Badiane et al. 2012). Berat rimpang cenderung menurun dengan meningkatnya cekaman air pada temulawak (Khaerana et al. 2008).

Cekaman air mengakibatkan proses fotosintesis terhambat sehingga jumlah asimilat yang dihasilkan oleh tanaman semakin berkurang dan produksi menurun (Sari et al. 2006). Besar kecilnya pengaruh tergantung pada fase pertumbuhan pada saat kekeringan terjadi dan lamanya kekeringan
(Ai et al. 2010). Pada penelitian jahe oleh Devy dan Nawfetrias (2012), ketersediaan air mempengaruhi berat kering rimpang jahe. Berat rimpang cenderung menurun seiring dengan meningkatnya periode cekaman air karena menyebabkan terganggunya transfer unsur hara dalam tanaman.

2. Kadar Kurkumin

Kurkumin merupakan salah satu produk senyawa metabolit sekunder kelompok fenolik dari tanaman Zingiberaceae, khususnya temulawak dan kunyit (Kristina et al. 2007). Metabolit sekunder dihasilkan oleh tanaman sebagai adaptasi pada kondisi lingkungan tertentu (Bourgaud 2001). Hasil analisis kadar kurkumin pada penelitian ini disajikan pada Gambar 1 dibawah ini.

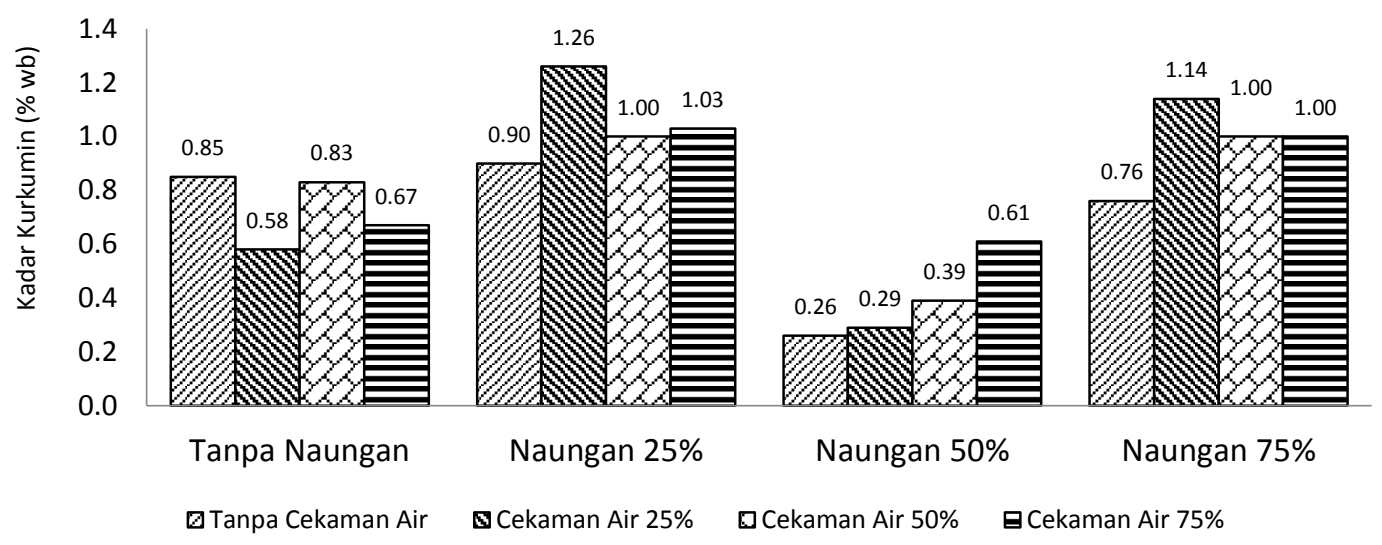

Gambar 1. Kadar kurkumin rimpang temulawak.

Berdasarkan gambar 1, kadar kurkumin meningkat pada naungan $25 \%$. Flavonoid dan fenol di daun maupun di rimpang lebih tinggi dibandingkan dengan intensitas cahaya penuh (Rahardjo 2010). Berdasarkan penelitian pada beberapa tanaman, diantaranya pada pada daun dan rimpang jahe total fenol menurun pada tingkat naungan 60\% (Ghazemzadeh et al. 2010), kandungan flavanoid pada pegagan cenderung sama pada naungan 55\% sampai 65\% (Musyarofah 2007), dan kandungan kurkumin pada kunyit meningkat pada tingkat naungan 59-73\% (Hossain 2009).

Kadar kurkumin temulawak meningkat padda perlakuan cekaman air. Kadar kurkumin pada perlakuan tanpa naungan meningkat pada perlakuan tanpa cekaman air. Pada naungan $25 \%$ dan $75 \%$ kadar kurkumin meningkat pada perlakuan cekaman air 25\%. Pada naungan 50\% kadar kurkumin meningkat pada perlakuan cekaman air 75\%. Peningkatan jumlah produksi total fenolat dan flavanoid pada kondisi kekurangan air disebabkan karena peningkatan aktivitas enzim fenilalanin amonia liase (PAL). Jaafar et al. (2012) menyatakan bahwa total fenolat, flavonoid, dan antosianin juga ditemukan lebih tinggi di bawah kondisi kekurangan air.

\section{KESIMPULAN DAN SARAN}

Kesimpulan yang dapat diambil dari hasil penelitian yaitu perlakuan tanpa cekaman air meningkatkan pertumbuhan dan hasil temulawak pada tiap naungan yang meliputi : jumlah tunas, jumlah daun, berat segar tanaman, berat kering tanaman, berat segar rimpang, berat simplisia, dan kadar kurkumin temulawak. Perlakuan naungan 50\% 
meningkatkan tinggi tanaman 196,50 $\mathrm{cm}$ dan perlakuan tanpa naungan meningkatkan jumlah daun tanaman 22,70 helai; berat segar tanaman 425,525 gram; dan berat kering tanaman 26,269 gram, namun tidak meningkatkan hasil rimpang temulawak.

Saran yang dapat penulis berikan pada budidaya temulawak adalah penyiraman pada fase awal pertumbuhan sebaiknya dilakukan dengan intensif sesuai dengan kebutuhan tanaman dan perlu dilakukan penelitian dengan faktor perlakuan intensitas naungan menggunakan naungan alami yang ada pada lahan.

\section{DAFTAR PUSTAKA}

Ai NS 2011. Biomassa dan kandungan klorofil total daun jahe (Zingiber officinale L.) yang mengalami cekaman kekeringan. $J$. Ilmiah Sains 11 (1) : 1-5.

Ai NS, Banyo Yunia 2010. Konsentrasi klorofil daun sebagai indikator kekurangan air pada tanaman. J. Ilmiah Sains 11 (2) : 166173.

Akram, Shahabuddin, Afzal A, Usmanghani K, Mohiuddin E, Asif MR 2010. Curcuma longa and curcumin: a review article. $J$. Biol. Plant Biol. 55 (2) : 65-70.

Badiane A, Ndour NY, Gueye F, Ibrahima N 2012. Effects of different inputs of organic matter on the response of plant production to a soil water stress in Sahelian Region. Nat. Sci 4(12) : 969-975.

Bae CY, Hwang JS, Choi S, Lim S, Kim J 2013. Physiological responses of Calystegia soldanella under drought stress. J. Ecol. Environ. 36 (4) : 255-265.

Bhuiyan A, Roy B, Sharma B, Rashid M 2012. Impact of multistoreyed agro-forestry systems on growth and yield of turmeric and ginger at Mymensingh, Bangladesh. eSci J. Crop Prod. 01 : 19-23.

Bourgaud F, Gravot A, Milesi S, Gontier E 2001. Production of plant secondary metabolites : a historical perspective. Plant Science 161 : 839-851.

BPS 2013. Luas panen, produksi, dan produktivitas tanaman obat-obatan, 2012. http://www.bps.go.id. Diakses pada $30 \mathrm{Juli}$ 2013.
Chaum S, Tuan NM, Phimmakong K, Kirdmanee C 2005. The ex vitro survival and growth of ginger (Zingiber officinale Rocs.) influence by in vitro acclimatization under high relative humidity and $\mathrm{CO}_{2}$ enrichment condition. Asian J. of Plant Science 4 (2) : 109-116.

Chaves et al. 2002. How plant cope in water stress in the field. photosynthesis and growth. Annals of Botani 89 (1) : 907-916.

Devy L, Nawfetrias W 2012. Pertumbuhan, kuantitas dan kualitas rimpang jahe (Zingiber Officinale Rosc.) pada cekaman kekeringan di bawah naungan. J. Sains dan Teknologi Indonesia 14 (3) : 216-220.

Ferry Y, Bambang ET, Randriani E 2009. Pengaruh intensitas cahaya dan umur panen terhadap pertumbuhan, produksi, dan kualitas hasil temulawak diantara tanaman kelapa Bul. Littro. 20 (2) : 131140.

Fitter AH, Hay RKM 1991. Fisiologi Lingkungan Tanaman. Diterjemahkan oleh Sri Andani dan E.D. Purbayanti. Editor B.Sri Gandono. Gadjah Mada University Press. Yogyakarta.

Ghasemzadeh A, Jaafar H, Rahmat A, Wahab P, Halim M 2010. Effect of different light intensities on total phenolics and flavonoids synthesis and anti-oxidant activities in young ginger varieties (Zingiber officinale Roscoe). Int. J. Mol. Sci. 11 : 3885-3897.

Hossain MA, Akamine H, Ishimine Y, Teruya R, Aniya Y, Yamawaki K 2009. Effects of relative light intensity on the growth, yield and curcumin content of turmeric (Curcuma longa L.) in Okinawa, Japan. Plant Prod. Sci. 12(1) : 29-36.

Jaafar H, Ibrahim MH, Fakri N 2012. Impact of soil field water capacity on secondary metabolites, phenylalanine ammonialyase (PAL), maliondialdehyde (MDA) and photosynthetic responses of Malaysian Kacip Fatimah (Labisia pumila Benth). Molecules 17 : 7305-7322.

Khaerana, Ghulamahdi M, Purwakusumah ED 2008. Pengaruh cekaman kekeringan dan umur panen terhadap pertumbuhan dan kandungan xanthorrhizol temulawak 
(Curcuma xanthorrhiza). Bul. Agron. 36 (3) : $241-247$.

Kristina N, Noveriza R, Syahid S, Rizal M 2007. Peluang peningkatan kadar kurkumin pada tanaman kunyit dan temulawak. Balai Penelitian Tanaman Obat Dan Aromatik.

Kurniasari AM, Adisyahputra, Rosman R 2010. Pengaruh kekeringan pada tanah bergaram $\mathrm{NaCl}$ terhadap pertumbuhan tanaman nilam. Bul. Littro. 21(1) : 18-27.

Kurniawati A, Darusman LK, Rachmawaty RY 2005. Pertumbuhan, produksi dan kandungan triterpenoid dua jenis pegagan (Centella asiatica L. (Urban)) sebagai bahan obat pada berbagai tingkat naungan. Bul. Agron. 33 (3) 62-67.

Musyarofah N, Susanto S, Aziz SA, Kartosoewarno S 2007. Respon tanaman pegagan (Centella asiatica L. Urban) terhadap pemberian pupuk alami di bawah naungan. Bul. Agron 35 (3) : 217 - 224.

Rahardjo M 2010. Pengaruh stres air, intensitas cahaya, konsentrasi karbondioksida dan salinitas terhadap parameter fisiologis dan morfologis tanaman jahe (Zingiber officinale Rosc.) status teknologi hasil penelitian jahe. Balai Penelitian Tanaman Obat dan Aromatik.

Raharjo M 2010. Penerapan SOP budidaya untuk mendukung temulawak sebagai bahan baku obat potensial. Perspektif 9 (2) : 78-93
Ramos ML, Parsons R, Sprent JI, James EK 2003. Effect of water stress on nitrogen fixation and nodule structure of common bean. Pesq. agropec. bras. 38 (3).

Salisbury FB, Ross CW 1995. Plant Physiology. 4rd Ed. Wadsworth Publishing Company. California.

Sari HC, Darmanti S, Hastuti ED 2006. Pertumbuhan tanaman jahe emprit (Zingiber Officinale Var. Rubrum) pada media tanam pasir dengan salinitas yang berbeda. Bul. Anatomi dan Fisiologi 14 (2) : 19-29.

Sirait J 2006. Dinamika nitrogen dan produksi rumput benggala (Panicum Maximum) pada tiga taraf naungan dan pemupukan. $J$. Nasional Teknologi Peternakan dan Veteriner 1(1) : 958-966.

Sukarjo EI 2004. Toleransi beberapa jenis Curcuma spp. terhadap intensitas naungan. J. Ilmu Pertanian Indonesia 6(2) : 97-103.

Thohirah LA, Flora C, Kamalakshi N 2010. Breaking bud dormancy and different shade levels for production of pot and cut Cucurma alismatifolia. American J. of Agric Biol. Sci. 5 (3): 385-388.

Yusron M 2009. Respon temulawak (Curcuma xanthorrhiza roxb.) terhadap pemberian pupuk bio pada kondisi agroekologi yang berbeda. J. Littri 15 (4) : 162-167. 